\title{
A Review of the Pattern of Malaria in Children above Neonatal Age at the University of Port Harcourt Teaching Hospital (2006-2011)
}

\author{
Yaguo-Ide Lucy Eberechukwu, ${ }^{1, *}$, Awopeju Abimbola Temitayo Oluwajenyo ${ }^{2}$ \\ ${ }^{1}$ Department of Paediatrics and Child Health, University of Port Harcourt Teaching Hospital, Port Harcourt, Nigeria \\ ${ }^{2}$ Department of Medical Microbiology and Parasitology, University of Port Harcourt Teaching Hospital, Port Harcourt, Nigeria
}

Copyright $(2018$ by authors, all rights reserved. Authors agree that this article remains permanently open access under the terms of the Creative Commons Attribution License 4.0 International License

\begin{abstract}
A retrospective study of children presenting with symptoms suggestive of malaria between 2006 and 2011 was carried out in the University of Port Harcourt Teaching Hospital. Sociodemographic data, clinical information and laboratory investigations were retrieved from the laboratory records of the medical microbiology department. Chi-square analysis was used to assess the prevalence of malaria in the different age groups and sexes. The results showed a $70 \%$ prevalence of malaria out of the 23698 patients reviewed. Malaria was significantly higher $\left(\chi^{2}=18.66, p<0.0001\right)$ in male patients compared to female patients There was a significantly higher $\left(\chi^{2}=6.76\right.$, p $=0.0093)$ prevalence $(72.70 \%)$ of malaria among children under 5 years and $593(3.47 \%)$ patients had severe malaria $(\geq 3+$ parasitemia). Severe anaemia, fever and bronchopneumonia were mostly associated with severe malaria. There was an average prevalence of $70.61 \%$ from 2006 to 2011 . The annual prevalence of malaria declined from $76.7 \%$ in 2009 to $60.6 \%$ in 2011 . The study showed a high prevalence of malaria among the patients, with children under 5 years being the most significantly affected.
\end{abstract}

Keywords Malaria, Parasitemia, Paediatric, Port Harcourt, Retrospective analysis

\section{Introduction}

Malaria is still a major cause of morbidity and mortality globally. [1] In 2010 it accounted for 655,000 deaths all over the world. Nigeria was responsible for $32 \%$ of thisdeath s. [1] It is endemic in Nigeria. [1] Malaria has remained a major cause of morbidity and mortality in Nigeria. [1] It has an all year round transmission, Plasmodium falciparum is the predominate specie transmitted by the anopheles mosquitos. [1]There has been a $20 \%$ decline in under-five mortality due to malaria from
2010 to 2013.[1] This decline could be attributed to the efforts of the National Malaria Control Strategic Plan (NMCSP) which include amongst others reducing malaria related mortality, reducing malaria parasite prevalence in children under age 5 , increasing possession and use of insecticide treated nets (ITNS) and long lasting insecticides nets, introducing and scaling up indoor residual spraying (IRS), increasing the use of diagnostic tests for fever patients, improving efforts related to appropriate and timely treatment of malaria and increasing coverage of intermittent preventive treatment of malaria during pregnancy.[1] According to the current Nigerian demographic and health survey 2013, malaria accounts for $20 \%$ under-five mortality.[1] There are about 3.3 billion people at risk for malaria, with about 247 million people affected yearly resulting in a million death mostly in children under the age of 5 years [2]. It accounts for about $50 \%$ of the out-patient hospital visits in endemic areas like Nigeria. [3]. Older children may serve as reservoirs for the transmission of malaria, leading to persistent asymptomatic infections [4]. There have been various reports of malaria among school age children, ranging from $11-26 \%$ prevalence especially among children between 8-16 years old malaria endemic countries [5-7].

The epidemiological patterns of malaria vary widely in the different regions of Nigeria, with infant malaria posing a major public health challenge. A retrospective review of the prevalence of malaria among children above the neonatal age presenting at the University of Port Harcourt Teaching Hospital, South-South, Nigeria between 2006 and 2011 was carried out in this study.

\section{Material and Methods}

\subsection{Study Design}

A retrospective analysis of laboratory records of paediatric patients suspected of malaria presenting at the 
University of Port Harcourt Teaching hospital between 2006 and 2011 was carried out.

\subsection{Study Area}

The study was carried out at the University of Port Harcourt Teaching hospital, a tertiary health care institution located in Port Harcourt, Rivers state, Nigeria. The hospital is a 500 bed capacity hospital which is also a referral center for the Niger-Delta area of Nigeria.

\subsection{Study Population}

The study population consisted of Paediatric patients (1 - 192months old) presenting with symptoms suggestive of malaria (fever, malaise, loss of appetite, pain, etc.) to the hospital. Patients between 1 - 192 months old were included in the study, while patients less than 1 month old were excluded from the study population.

\subsection{Data Collection}

Data on age, sex, clinical diagnosis, associated conditions, laboratory diagnosis and results of the study population were collected from the data register of the department of medical microbiology of the hospital.

\subsection{Diagnosis of Malaria}

Malaria diagnosis was done by the microscopic examination of Geimsa-stained thin film blood smears from each patient according to standard protocol Ojurongbe et al [5].

\subsection{Data Analysis}

The Epi Info statistical software v7 (CDC, USA) was used to analyze the data collected. The Student's T-test was used to determine the difference in the age groups among patients positive for malaria and those negative for malaria. Chi-square was used to determine the difference in the proportion of occurrence of malaria in the patients according to sex. A p-value of $<0.05$ was considered significant and all tests was carried out at a $95 \%$ confidence interval.

\section{Results}

Table 1. Sociodemographic distribution of patients

\begin{tabular}{ccc}
\hline Age $($ Mean \pm S.E) & \multicolumn{2}{c}{$\mathbf{4 2 . 4 \pm 0 . 3}$ months } \\
\hline Sex & Frequency & Percent \\
Male & 13113 & $55.33 \%$ \\
Female & 10585 & $44.67 \%$ \\
Total & $\mathbf{2 3 6 9 8}$ & $\mathbf{1 0 0 . 0 0 \%}$ \\
\hline
\end{tabular}

Table 1 shows that the mean age of the patients was
$42.4 \pm 0.3$ months. There were 13113 (55.33\%) male subjects and 10585 (44.67\%) female patients, M:F ratio 1.2: 1

Fig 1 shows that $17116(70 \%)$ of the patients were confirmed to have malaria and $6582(28 \%)$ of the patients were negative for malaria.

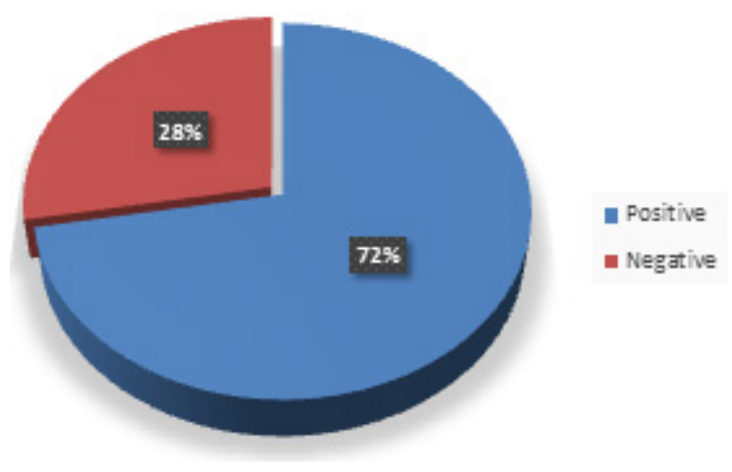

Figure 1. Frequency of malaria in patients

Table 2 showed a significant difference between patients positive for malaria and patient that did not have malaria $\left(\chi^{2}: 18.66 ; p<0.0001\right)$. There were 9619 male patients and 7497 female patients with malaria.

Table 2. Distribution of malaria according to sex

\begin{tabular}{|c|c|c|c|}
\hline SEX & $\begin{array}{c}\text { Positive } \\
(n, \%)\end{array}$ & $\begin{array}{c}\text { Negative } \\
(n, \%)\end{array}$ & $\begin{array}{c}\text { Chi-square } \\
\text { (p-value) }\end{array}$ \\
\hline Male & $\begin{array}{c}9619 \\
(56.20)\end{array}$ & 3494 (53.08) & \multirow{3}{*}{$18.66(<0.0001)^{*}$} \\
\hline Female & $\begin{array}{c}7497 \\
(43.80)\end{array}$ & 3088 (46.92) & \\
\hline Total & $\begin{array}{c}17116 \\
(100.00)\end{array}$ & $6582(100.0)$ & \\
\hline
\end{tabular}

Table 3 shows that $12443(72.70 \%)$ of the patients positive for malaria were below the age of 5 years, 3269 $(19.10 \%)$ were between 5 -10years old and 1404 (8.20) were between $10-16$ years old. There was a statistically significant occurrence of malaria among the children under 5 years $\left(\chi^{2}=6.76, p=0.0093\right)$. The occurrence of malaria in the age groups above 5 years old was not statistically significant $(p>0.05)$

Table 3. Occurrence of Malaria according to age groups

\begin{tabular}{cccc}
\hline $\begin{array}{c}\text { Age group } \\
\text { (years) }\end{array}$ & $\begin{array}{c}\text { Positive } \\
(\mathbf{n}, \mathbf{\%})\end{array}$ & $\begin{array}{c}\text { Negative } \\
(\mathbf{n}, \mathbf{\%})\end{array}$ & $\begin{array}{c}\text { Chi-square } \\
\text { (p-value) }\end{array}$ \\
\hline$<5$ & 12443 & $4895(74.37)$ & $6.76(0.0093)^{*}$ \\
$5-10$ & $3269(12.70)$ & $1190(18.08)$ & $3.23(0.0721)^{* *}$ \\
$10-16$ & $1404(8.20)$ & $497(7.55)$ & $2.73(0.0979)^{* *}$ \\
Total & $\begin{array}{c}\mathbf{1 7 1 1 6} \\
\mathbf{( 1 0 0 . 0 0 )}\end{array}$ & $\mathbf{6 5 8 2}(\mathbf{1 0 0 . 0 )}$ & \\
\hline
\end{tabular}

*Difference is statistically significant $(\mathrm{p}<0.05)$

The microscopic grading of parasitemia in the patients showed that $13257(77.45 \%)$ cases of malaria with $1+$, $3266(19.08 \%)$ with $2+$, while $593(3.47 \%)$ had $\geq 3+$ parasitemia as shown in Table 4 . 
Table 4. Microscopic enumeration of malaria parasite

\begin{tabular}{ccc}
\hline Grading & Frequency (n) & Percent (\%) \\
$1+$ & 13257 & 77.45 \\
$2+$ & 3266 & 19.08 \\
$\geq 3+$ & 593 & 3.47 \\
Total & $\mathbf{1 7 1 1 6}$ & $\mathbf{1 0 0 . 0 0 \%}$ \\
\hline
\end{tabular}

There was severe complicated malaria in 348 (3.62\%) of the male patients and $245(3.27 \%)$ of the female patients, while 9271 (96.38\%) of the male patients and 7252 $(96.73 \%)$ of the female patients had acute non severe malaria (Table 5).

Table 5. Severity of malaria by sex

\begin{tabular}{cccc}
\hline $\begin{array}{c}\text { Malaria } \\
\text { Grade }\end{array}$ & $\begin{array}{c}\text { Male } \\
(\mathbf{n}, \mathbf{\%})\end{array}$ & $\begin{array}{c}\text { Female } \\
(\mathbf{n}, \mathbf{\%})\end{array}$ & $\begin{array}{c}\text { Chi-square } \\
\text { (p-value) }\end{array}$ \\
\hline Mild & 9271 & 7252 & \\
& $(96.38)$ & $(96.73)$ & \\
Severe & $348(3.62)$ & $245(3.27)$ & $1.54(0.2143) * *$ \\
& $\mathbf{9 6 1 9}$ & $\mathbf{7 4 9 7}$ & \\
Total & $\mathbf{( 1 0 0 . 0 )}$ & $\mathbf{( 1 0 0 . 0 )}$ & \\
\hline
\end{tabular}

$* *$ difference between both groups is not statistically significant $(\mathrm{p}>0.05)$

Table 6. Severity of malaria according to age group

\begin{tabular}{|c|c|c|c|}
\hline $\begin{array}{l}\text { Age group } \\
\text { (years) }\end{array}$ & $\begin{array}{c}\text { Severe malaria } \\
(\mathbf{n}, \%)\end{array}$ & $\begin{array}{l}\text { Mild malaria } \\
(\mathrm{n}, \%)\end{array}$ & $\begin{array}{c}\text { Chi-square } \\
\text { (p-value) }\end{array}$ \\
\hline$<5$ & $402(67.8)$ & $12733(77.1)$ & $\begin{array}{c}27.56 \\
(<0.0001)^{*}\end{array}$ \\
\hline $5-10$ & $129(21.8)$ & $2448(14.8)$ & $\begin{array}{c}19.81 \\
(<0.0001)^{*}\end{array}$ \\
\hline $11-16$ & $62(10.5)$ & $1342(8.1)$ & $\begin{array}{c}4.13 \\
(0.0419)^{*}\end{array}$ \\
\hline Total & $593(100.0)$ & $16523(100.0)$ & \\
\hline
\end{tabular}

*difference between the groups is statistically significant $(\mathrm{p}<0.05)$

The distribution of severe malaria according to age groups showed that severe malaria was significantly high ( $\mathrm{p}<0.0001)$ among children under 5 years $(67.8 \%)$, followed by children between $5-10$ years $(21.8 \%)$ and children between $11-16$ years old $(10.5 \%)$ as shown in Table 6.

Table 7 shows the associated diagnosis and severe malaria, $155(26.2 \%)$ had severe anaemia, $109(18.4 \%)$ had fever, 81 (13.6\%) had bronchopneumonia, $52(13.6 \%)$ had tonsillitis, 35 (5.8\%) had sickle cell disease, 35 (5.8\%) had URTI, 29 (4.9\%) had septicemia, 23 (3.9\%) had diarrhea and sepsis respectively, 17 (2.9\%) had dysentery and 12 $(1.9 \%)$ had hyperpyrexia

Table 7. Associated Conditions and severe malaria

\begin{tabular}{ccc}
\hline $\begin{array}{c}\text { Associated } \\
\text { Conditions }\end{array}$ & Frequency (n) & Percent (\%) \\
\hline Severe anaemia & 155 & 26.2 \\
Fever & 109 & 18.4 \\
Bronchopneumonia & 81 & 13.6 \\
Tonsillitis & 52 & 8.7 \\
Sickle cell disease & 35 & 5.8 \\
URTI & 35 & 5.8 \\
Septicaemia & 29 & 4.9 \\
Diarrhoea & 23 & 3.9 \\
Sepsis & 23 & 3.9 \\
Urinary tract infection & 23 & 3.9 \\
Dysentery & 17 & 2.9 \\
Hyperpyrexia & 12 & 1.9 \\
Total & $\mathbf{5 9 3}$ & $\mathbf{1 0 0 . 0}$ \\
\hline
\end{tabular}

*Note: associated conditions are not mutually exclusive

Fig 2 shows that occurrence of malaria ranged from $63.5 \%$ to $65.7 \%$ between January and April, while it ranged from $68.1 \%$ to $75.0 \%$ between May and August. There was a decline in occurrence from $73.5 \%$ to $58.0 \%$ from September to December.

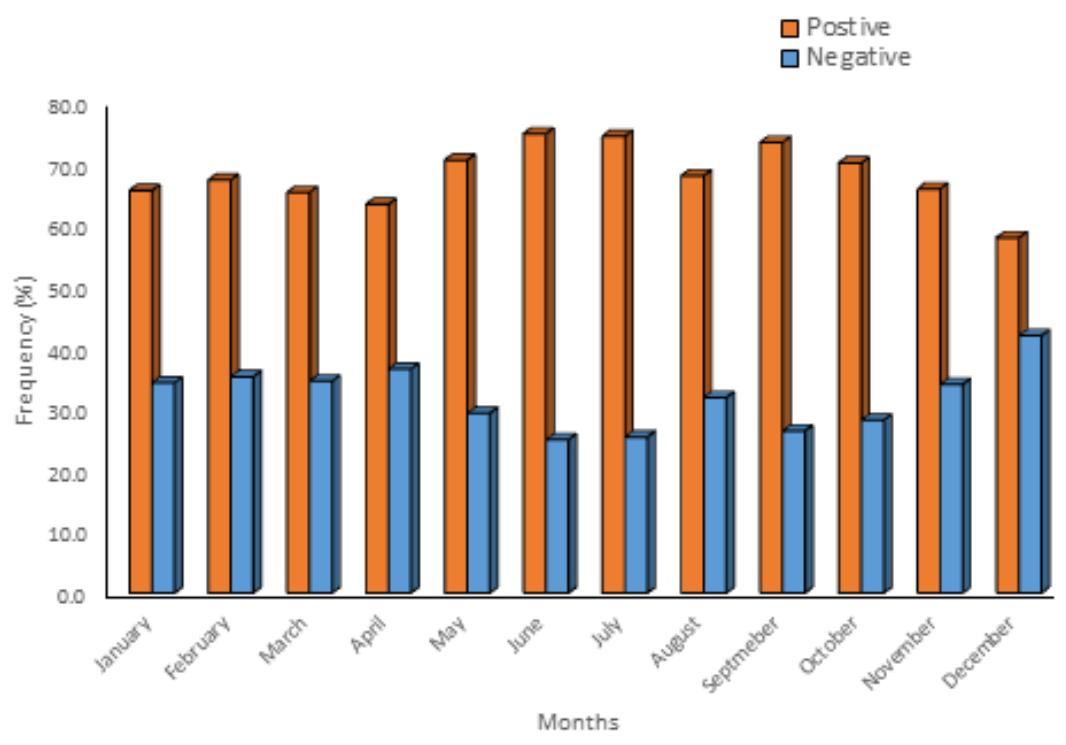

Figure 2. Occurrence of malaria according to months 


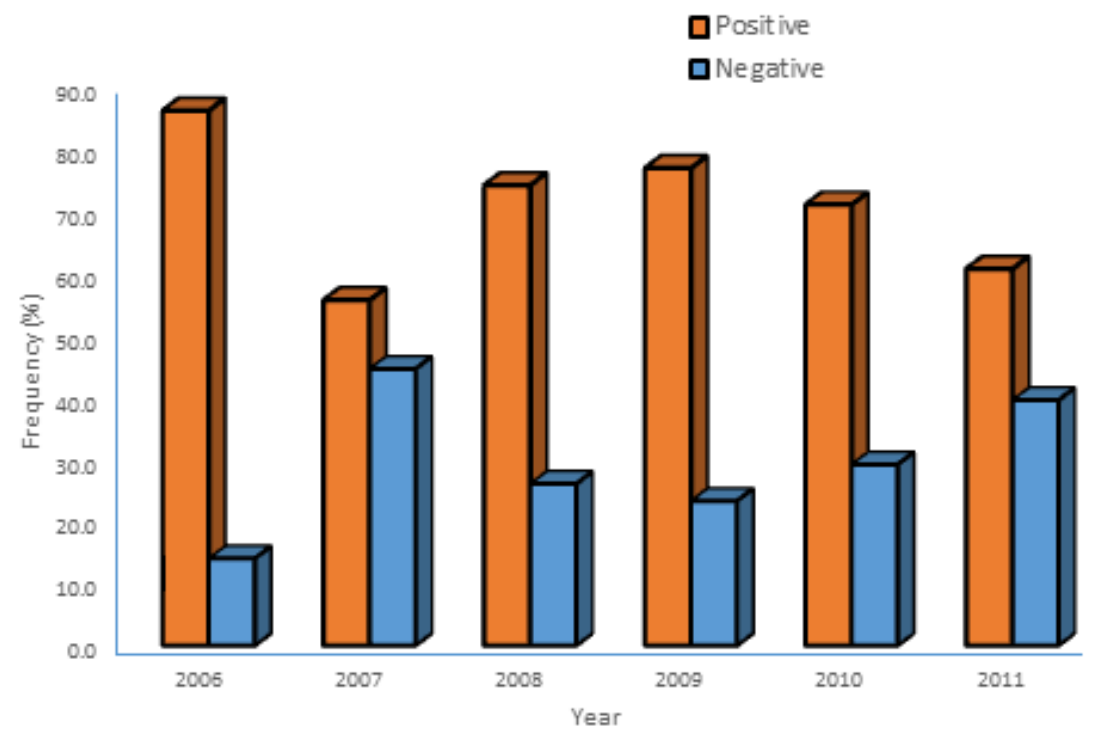

Figure 3. Frequecny of malaria positive cases according years

There was an average prevalence of $70.61 \%$ from 2006 to 2011 . The Proportion of positive malaria cases include, $86.0 \%$ in $2006,55.5 \%$ in $2007,74.0 \%$ in $2008,76.7 \%$ in $2009,70.9 \%$ in 2010 and $60.6 \%$ in 2011 as shown in Fig 3.

\section{Discussion}

There was a $70 \%$ prevalence of malaria among all the patients seen, with $72.7 \%$ of the patients with malaria being under the age of five. This is consistent with the $70 \%$ transmission rate reported by the WHO in 2015 [8], and prevalence rates between $73-80 \%$ reported in other studies across Nigeria [9-11]. This high prevalence may be attributed to the endemic nature of malaria in Nigeria and the large tropical rainforest area of Rivers state. Implications on this high prevalence may include anemia [12], poor cognitive function due to cerebral malaria [13] and increased mortality among school-age children [14].

The occurrence of malaria was significantly higher in children under 5 years old (72.7\%). Among the patients with severe malaria, children under the age of 5 years was also significantly affected $(67.8 \% ; \mathrm{p}<0.0001)$. This is similar to the findings of previous studies indicating severe malaria significantly occurs in children below 5 years especially in malaria endemic regions. The Nigerian demographic and Health Survey final report of 2013 also reports that children under age 5 and pregnant women are the groups most vulnerable to illness and death from malaria infection in Nigeria. [1, 10-16]. Severe anaemia, fever and bronchopneumonia $(26.2 \%, 18.4 \%$ and $13.6 \%$ respectively) was mostly seen among patients with severe malaria. These conditions have been associated with severe malaria in different studies [6, 13, and 15]. These conditions have also been shown to impair effective immune response to malaria leading to progression of symptoms [16].

The endemic nature of malaria in a country like Nigeria, also translates to continuous exposure to mosquito bites and transmission of malaria parasite that ultimately leads to the formation of high affinity antibodies that inhibit parasite growth and disease progression [1, 17].

The study showed that occurrence of malaria peaked during the period of heavy rain (May - July) in the country. This is in agreement with the reports of Olasehinde et al., which reported a peak in the occurrence of malaria during the period of heavy rain fall Nigeria [10]. There is an increase in the pools of stagnant water, leading to an increase in the mosquito population which increases the rate of parasite transmission [18].

There was an average prevalence of $70.61 \%$ between 2006 and 2011, with a decline in prevalence of malaria from $76.7 \%$ to $60.6 \%$ observed from 2009 to 2011 . The decline in prevalence may be attributed to efforts by the NMCSP which include amongst others reducing malaria related mortality, reducing malaria parasite prevalence in children under age 5 , increasing possession and use of insecticide treated nets (ITNS) and long lasting insecticides nets, introducing and scaling up indoor residual spraying (IRS), increasing the use of diagnostic tests for fever patients, improving efforts related to appropriate and timely treatment of malaria and increasing coverage of intermittent preventive treatment of malaria during pregnancy.( intermittent preventive treatment using sulphadoxine-pyramethamine (IPT-SP) treatment for malaria control in Africa) $[1,18,19]$.

\section{Conclusions}

Malaria was significantly more prevalent in children under 5 years. Though there was a decline in prevalence 
from $76.7 \%$ to $60.6 \%$ between 2009 and 2011 , there is need for intensified efforts in curbing the menace of malaria, especially in children to prevent and reduce child mortality.

\section{Authors' Contribution}

Author 1 collected the data and prepared the document. Author 2 managed the literature search

\section{REFERENCES}

[1] Nigeria Demographic and Health Survey Final Report 2013

[2] WHO (2008). World Health Organization, Geneva. WHO World Malaria Report, 2015. WHO/HTM/GMP/2008.1.

[3] Agomo CO, Oyibo WA, Anorlu RI, Agomo PU. Prevalence of Malaria in Pregnant Women in Lagos, South-West Nigeria. Korean J. Parasitol, 2009; 47(2): 179-183.

[4] Walldorf JA, Cohee LM, Coalson JE, Bauleni A, Nkanaunena K, Kapito-Tembo A, et al. School-Age Children Are a Reservoir of Malaria Infection in Malawi. PLoS ONE 2015; 10(7): e0134061. doi:10.1371/journal.pone.0134061.

[5] Ojurongbe OAM, Adegbayi OS, Bolaji AA, Akindele OAA, Adeyeba OA. Asymptomatic falciparum Malaria and Intestinal Helminths Co-Infection among School Children in Osogbo, Nigeria. Jour Res Med Sci, 2011; 16: 680-6.

[6] Noor AM, Kinyoki DK, Mundia CW, Kabaria CW, Mutua JW. The Changing Risk of Plasmodium falciparum Malaria Infection in Africa: 2000-10: A Spatial and Temporal Analysis of Transmission Intensity. Lancet 2014; 383 (9930): 1739-47.

[7] O’Meara WP, Mangeni JN, Steketee R, Greenwood B. Changes in the Burden of Malaria in Sub-Saharan Africa. Lancet Infect Dis. 2010; 10 (8): 545-555.

[8] WHO malaria profile 2015. Available at http://www.who.int/malaria/publications/country-profiles/ profile_nga_en.pdf. Accessed on 27/02/2017.

[9] Kalu MK, Nwogo AO, Nduka FO, Otuchristian G. A comparative study of the prevalence of Malaria in Aba and Umuahia urban areas of Abia State, Nigeria. Res Jour Para.
2012; 7: 17-24.

[10] Olasehinde GI, Ajayi AA, Taiwo SO, Adekeye BT, Adeyeba OA. Prevalence and Management of Faciparium Malaria among infants and children in Ota, Ogun State, South western Nigeria. Afri Jour Clin \& Exp Micro, 2010; 11: 159-163.

[11] Madukosiri CH, Bawo DS. Illness pattern and the relationship between the Prevalence of malaria and other infections in Niger Delta University. Agric \& Bio Jour Nor Am, 2011; 20(2): 2151-7525.

[12] Kassebaum NJ, Jasrasaria R, Naghavi M. A systematic analysis of global anemia burden from 1990 to 2010. Blood, 2014; 123, 615-624.

[13] Nankabirwa J, Wandera B, Kiwanuka N, Staedke SG, Kamya MR and Brooker SJ Asymptomatic plasmodium infection and cognition among primary schoolchildren in a high malaria transmission setting in Uganda. Am J Trop Med \& Hyg 2013; 88: 1102-1108.

[14] Murray CJ, Rosenfeld LC, Lim SS. Global malaria mortality between 1980 and 2010: a systematic analysis. The Lancet 2012; 379, 413-431.

[15] Kimbi HK, Sumbele IU, Nweboh M. Malaria and haematologic parameters of pupils at different altitudes along the slope of Mount Cameroon: a cross-sectional study. Malaria Journal 2013; 9: 193.

[16] Alessandro U, Ubben D, Hamed K, Ceesay AJ, Okebe J, Taal M, Lama EK, Keita M, Koivogui L, Nahum A, Bojang K, Sonko AA, Lalya HF, Brabin B. Malaria in infants aged less than six months - is it an area of unmet medical need? Malaria Journal, 2012, 11:400 - 405

[17] Mboera LE, Senkoro KP, Rumisha SF. Plasmodium falciparum and helminth coinfections among schoolchildren in relation to agro-ecosystems in Mvomero District, Tanzania. Acta Tropica, 2011; 120: 95-110.

[18] Nankabirwa J, Simon JB, Clarke SE, Fernando D, Gitonga $\mathrm{CW}$, Schellenberg D, Greenwood B. Malaria in school-age children in Africa: an increasingly important challenge Trop Med \& Int Hea, 2014; 19(2): 1294-1309.

[19] Intermittent Preventive Treatment for infants using sulfadoxine-pyrimethamine (IPT-SP) for malaria control in Africa: implementation filed guide September 2011. World Health Organization, United Nations children fund. Available at http://whqlibdoc.who.int/hq/2011/WHO_IVB _11.07_eng.pdf. Accessed on 14 March, 2017 